Check for updates

Cite this: RSC Adv., 2019, 9, 17824

Received 1st April 2019

Accepted 30th May 2019

DOI: $10.1039 / c 9 r a 02449 b$

rsc.li/rsc-advances

\title{
Nanocellulose supported hierarchical structured polyaniline/nanocarbon nanocomposite electrode via layer-by-layer assembly for green flexible supercapacitors $\dagger$
}

\author{
Shaoyi Lyu, (D) *a Yanping Chen, ${ }^{\text {ab }}$ Longfei Zhang, ${ }^{\text {ac }}$ Shenjie Han, ${ }^{\text {a }}$ Yun Lu, (D) ${ }^{a}$ \\ Yuan Chen, (D) ${ }^{a}$ Na Yang, ${ }^{a}$ Zhilin Chen ${ }^{a}$ and Siqun Wang (D) *ac
}

\begin{abstract}
The development of a hierarchical structured multicomponent nanocomposite electrode is a promising strategy for utilizing the high efficiency of an electroactive material and improving the electrochemical performance. We propose cellulose nanofibril (CNF) aerogels with a nanoscale fiber-entangled network as the skeleton (via layer-by-layer (LbL) assembly) of electroactive materials polyaniline (PANi), carboxylic multiwalled carbon nanotubes (CMWCNTs), and graphene oxide (GO) to obtain structurally ordered polymer-inorganic hybrid nanocomposite electrodes for high-capacity flexible supercapacitors. The uniformly distributed multilayer nanoarchitecture, interconnected network, and hydrophilicity of the electrode provide a high specific surface area, excellent ion diffusion channels, and large effective contact area, thereby improving the electrochemical performance of the supercapacitor electrode. The specific capacitance of the CNF-[PANi/CMWCNT $]_{10}\left(\mathrm{CPC}_{10}\right)$ and CNF-[PANi/RGO $]_{10}\left(\mathrm{CPR}_{10}\right)$ electrodes reaches 965.80 and $780.64 \mathrm{~F} \mathrm{~g}^{-1}$ in $1 \mathrm{M}$ aqueous $\mathrm{H}_{2} \mathrm{SO}_{4}$ electrolyte, respectively; the corresponding values in $\mathrm{PVA} / \mathrm{H}_{3} \mathrm{PO}_{4}$ electrolyte are 1.59 and $1.46 \mathrm{~F} \mathrm{~cm}^{-2}$. In addition, the assembled symmetric supercapacitors show good energy densities of 147.23 and $112.32 \mathrm{~mW} \mathrm{~h} \mathrm{~cm}$, as well as excellent durability and flexibility. Our approach offers a simple and effective method for fabricating an ideal wellstructured nanocomposite electrode for green and flexible energy storage devices via LbL assembly.
\end{abstract}

\section{Introduction}

The increasing demand for green flexible electronic devices, portable microelectronic products, and wearable devices, as well as environmentally-friendly new energy products, has triggered in-depth studies on low-cost flexible electrode materials with high capacity, high speed, long life, high stability, and good biodegradability/biocompatibility. ${ }^{1-5}$ Supercapacitors are the most promising solution to the abovementioned requirements and hence have become a hot topic of research. ${ }^{6-10} \mathrm{~A}$ possible strategy to achieve high specific capacitance, high operating potential, and long-term cycle stability of supercapacitors involves hybridizing a double layer capacitance

\footnotetext{
${ }^{a}$ Research Institute of Wood Industry, Chinese Academy of Forestry, Hunan Collaborative Innovation Center for Effective Utilizing of Wood \& Bamboo Resources, Beijing 100091, China. E-mail: lvsy@caf.ac.cn

${ }^{b}$ Beijing Engineering Research Center of Cellulose and Its Derivatives, School of Materials Science and Engineering, Beijing Institute of Technology, Beijing 100081, China

${ }^{c}$ Center for Renewable Carbon, University of Tennessee, Knoxville, Tennessee, 37996, USA.E-mail:swang@utk.edu
}

$\dagger$ Electronic supplementary information (ESI) available. See DOI: 10.1039/c9ra02449b
(EDLC) carbon material with a pseudocapacitance conductive polymer material; this method allows for efficient charge transfer and accelerates the reaction kinetics. ${ }^{11-15}$

Layer-by-layer (LbL) assembly has been demonstrated to be an effective method to produce carbon material/conductive polymer nanocomposite electrode materials. ${ }^{16-19}$ The strong affinity between the constituent materials affords a polymer-inorganic hybrid with a hierarchical nanostructure. However, since the conventional and mature LbL assembly method uses a glass (ITOcoated glass) or polymer film (PET, PDMS, PLA, and nanocellulose film) as a carrier, it suffers from insufficient mass loading of the active material. ${ }^{20,21}$ This is because the active material adheres only to the surface of the glass or film and does not penetrate deeper into the glass or film to form more deposition. Hence, it is unsuitable for application to the large-scale, controlled fabrication of flexible supercapacitor electrodes with high energy and power densities. One of the novel concepts in this regard is the use of biomass-based aerogels as carriers for the LbL assembly. ${ }^{22,23}$ The porous structure of the aerogel with porosity of $\sim 99 \%$ and pore diameter of $\sim 50 \mathrm{~nm}$ can allow the active material to enter its interior for deposition. ${ }^{24,25}$ However, the reported aerogels are mostly nanosheet structures, rather than nanofibrillar structures. This results in a lower specific surface area and does not maximize 
the electrochemical performance of the active material attached thereto. If the aerogels have three-dimensional (3D) fibrous network structure, the rugged interconnected fibrous network and large specific surface area of the aerogels would lead to excellent electrochemical performance of the template electrode and greatly improve the flexibility of the electrode.

In this paper, we report the fabrication of a polymer-inorganic hybrid nanocomposite electrode by the hierarchical assembly of polyaniline (PANi)/carboxylic multiwalled carbon nanotubes (CMWCNTs) and PANi/graphene oxide (GO) multilayers on cellulose nanofibril (CNF) aerogels with a nanoscale fiber-entangled network. PANi, CMWCNT, and GO carrying opposite charges were allowed to penetrate the CNF aerogels by vacuum filtration and coated onto the nanofibers in an LbL fashion. CNF is a promising biomass nanomaterial with has an abundance of hydroxyl groups, and it shows excellent structural stability, high mechanical strength and low thermal expansion. Hence, CNF has been used in many applications such as biosensors and energy storage devices. ${ }^{26,27}$ PANi, CMWCNT, and GO and their composites are among the hottest energy storage materials currently researched. The 3D fibrous networks of the CNF aerogels not only provide a good LbL assembly platform for the PANi/CMWCNT (abbreviated as PC) or PANi/GO (abbreviated as PG) composite electrode, but also increase the specific surface area of the electrode and promote the transport and permeation of the electrolyte ions into the electrode. The resulting flexible composite electrodes exhibit homogeneous distribution of multicomponent micro/nanoarchitectures, with a high areal capacitance of $1.59 \mathrm{~F} \mathrm{~cm}^{-2}$ and high areal specific energy of $147.23 \mathrm{~mW} \mathrm{~h} \mathrm{~cm}^{-2}$ in a two-electrode test.

\section{Experimental procedure}

\section{Materials}

CNF was prepared from wood bleached kraft pulps with promoted Isogai method..$^{28} \mathrm{GO}$ suspensions $\left(2 \mathrm{mg} \mathrm{mL}{ }^{-1}\right.$, flake diameters: $0.5-2 \mu \mathrm{m}$ ) and CMWCNT (OD < $10 \mathrm{~nm}$, length: $0.5-3$ $\mu \mathrm{m},-\mathrm{COOH}$ content: $3.88 \mathrm{wt} \%$ ) were purchased from XFNANO. PANi (emeraldine base, average $M_{\mathrm{w}}: 50000$ ) was purchased from Sigma Aldrich. 1,2,3,4-Butanetetracarboxylic acid (BTCA) and sodium hypophosphite (SHP) were purchased from Aladdin. tert-Butanol, hydrazine hydrate, dimethylacetamide (DMAc) and hydrochloric acid were purchased from the Sinopharm Chemical Reagents Company.

\section{Preparation of the CNF aerogels}

$0.3 \mathrm{wt} \% \mathrm{CNF}$ dispersions were dispersed with tert-butanol/water mixed solution in a $2: 3(\mathrm{w} / \mathrm{w})$ ratio using an ultrasonic processor (VCX $1500 \mathrm{HV}$, Sonics \& Materials Inc.) at $500 \mathrm{~W}$ for $30 \mathrm{~min}$. The amount of BTCA added is $1 / 2$ of the dry weight of CNF. The amount of SHP added is $1 / 2$ of BTCA. The addition of BTCA/SHP $(2: 1 \mathrm{w} / \mathrm{w})$ plays a role in micro-cross-linking. The aqueous dispersions were subsequently frozen in cylindrical plastic moulds at $-30{ }^{\circ} \mathrm{C}$ for $12 \mathrm{~h}$, followed by lyophilisation in a freeze dryer (LGJ-10D, Beijing Four-Ring Science Instrument Plant Co., Ltd). The resulting freeze-dried aerogels were heated at $175{ }^{\circ} \mathrm{C}$ for $5 \mathrm{~min}$ to ensure sufficient covalent cross-linking.

\section{Preparation of PANi, CMWCNT, and GO suspensions}

Briefly, $1 \mathrm{~g}$ PANi (emeraldine base) was added into $50 \mathrm{~mL}$ DMAc, and the mixture was stirred for about $10 \mathrm{~h}$ using a magnetic stirrer. $5 \mathrm{~mL}$ of the above mixture was taken out and added to $45 \mathrm{~mL}$ of a pH $3 \mathrm{HCl}$ solution. Then, it was ultrasonically dispersed for 1 hour at $500 \mathrm{~W}$ in an ice-water bath. The resulting PANi (emeraldine salt) dispersion was diluted to $0.5 \mathrm{mg} \mathrm{mL}^{-1}$ with ultrapure water, and then the $\mathrm{pH}$ of the solution was adjusted to 2.5 with $1 \mathrm{M} \mathrm{HCl}$. CMWCNT powder $(0.1 \mathrm{~g})$ was dispersed in ultrapure water $(200 \mathrm{~mL})$ and ultrasonically dispersed for 1 hour at $500 \mathrm{~W}$ in an ice-water bath to obtain a $0.5 \mathrm{mg} \mathrm{mL}{ }^{-1}$ CMWCNT suspension. Using ultrapure water to dilute GO suspension to $0.5 \mathrm{mg} \mathrm{mL} \mathrm{m}^{-1}$ and ultrasonically dispersed for 1 hour at $500 \mathrm{~W}$.

\section{LbL assembly of the aerogel electrodes}

The nano active materials with opposite charges were assembled inside the aerogels by vacuum filtration. The PANi, CMWCNT, and GO suspensions can be penetrated into the CNF aerogel through a controlled low negative pressure vacuum filtration method. First, the PANi suspension is fully dripped onto the surface of CNF aerogel to make it fully swell and maintain for 15 minutes. Then the vacuum filtration is carried out to remove the PANi. Then, in the same way, the suspension of CMWCNT or GO is dripped onto the surface of CNF aerogel, and 15 min remains after it is fully expanded. This process was repeated to allow the LbL assembly. The assembled aerogels were dialysed by placing them in large amounts of ultrapure water in order to remove residual hydrochloric acid and DMAc, and then freeze-dried after freezing in liquid nitrogen to obtain the desired aerogel electrodes. The resulting aerogel electrodes are referred to as CNF$[\mathrm{PANi} / \mathrm{CMWCNT}]_{n}$ (abbreviated as $\mathrm{CPC}_{n}$ ) or $\mathrm{CNF}-[\mathrm{PANi} / \mathrm{GO}]_{n}$ (abbreviated as $\mathrm{CPG}_{n}$ ), where the subscripts $n$ refers to the number of assemblies. In order to obtain better electrochemical performance, the $\mathrm{CNF}-[\mathrm{PANi} / \mathrm{GO}]_{n}$ aerogel was reduced using hydrazine hydrate and ammonia in an autoclave at $90{ }^{\circ} \mathrm{C}$ for $2 \mathrm{~h}$ to form a CNF-[PANi/RGO $]_{n}$ (abbreviated as $\mathrm{CPR}_{n}$ ) aerogel.

\section{Characterisation and electrical measurements}

The sizes and zeta potentials of PANi, CMWCNT, and GO were tested by a Zetasizer Nano ZS instrument (Malvern Instruments Ltd., UK). Fourier transform infrared (FTIR) spectra were measured on a Nicolet iS10 spectrometer (Thermo Fisher Scientific Inc., USA). Raman spectroscopy was recorded using an inVia confocal Raman microscope with diode-laser excitation at $632.8 \mathrm{~nm}$ at room temperature (Renishaw, UK). X-ray diffraction (XRD) experiments were conducted using a D8 Advance diffractometer (Bruker Co., Germany) with $\mathrm{Cu} \mathrm{K} \alpha$ radiation $(\lambda=0.154 \mathrm{~nm}, 40 \mathrm{kV}, 40 \mathrm{~mA})$ in the $5-60^{\circ} 2 \theta$ range. $\mathrm{X}$ ray photoelectron spectroscopy (XPS) was recorded on an ESCALAB 250Xi instrument with an $\mathrm{Al} \mathrm{K} \alpha(h \nu=1486.6 \mathrm{eV}) \mathrm{X}$-ray source set at $20 \mathrm{~mA}$ (Thermo Fisher Scientific Inc., USA). Scanning electron microscopy (SEM) was performed using an S-4800 field-emission-gun SEM instrument (Hitachi, Japan) at $5.0 \mathrm{kV}$. Transmission electron microscopy (TEM, Tecnai G $^{2}$ F30, FEI, 
USA) was used to characterise the microstructures of the aerogels. Specific surface areas (Brunauer-Emmett-Teller, BET) and pore structure (Barret-Joyner-Halenda, BJH) were calculated using $\mathrm{N}_{2}$-gas-adsorption isotherms (NOVA 1200e Quantachrome, USA). Conductivities were measured using an ST 2253 4point probe resistivity measurement system (Suzhou Jingge Electronic Co., Ltd, China). Tensile strength were measured on an Instron 5848 instrument (Instron Co., USA).

Electrochemical measurements were conducted using a CHI $660 \mathrm{E}$ electrochemical workstation (Shanghai Chenhua Instrument Co., LTD, China) at $25{ }^{\circ} \mathrm{C}$. Each aerogel electrode was compressed at $1 \mathrm{MPa}$ into a film electrode for the subsequent electrochemical test (Fig. S2b and $\mathrm{c}^{\dagger}$ ). A three-electrode system was employed in $1 \mathrm{M}$ aqueous $\mathrm{H}_{2} \mathrm{SO}_{4}$ electrolyte, in which a saturated calomel electrode (SCE) and a Pt electrode were used as the reference and counter electrode, respectively. In the three-electrode test, the electrode was only connected with aluminum sheet and the electrode itself acted as a current collector. The electrochemical experiments of the symmetrical flexible all-solid-state supercapacitor were performed using the $\mathrm{PVA} / \mathrm{H}_{3} \mathrm{PO}_{4}$ electrolyte by a two-electrode system. A PVA $/ \mathrm{H}_{3} \mathrm{PO}_{4}$ electrolyte was prepared by mixing PAV (6 g), $\mathrm{H}_{3} \mathrm{PO}_{4}(6 \mathrm{~g})$ and deionized water $(60 \mathrm{~mL})$, and heating to $80{ }^{\circ} \mathrm{C}$ until the solution was clarified. The symmetrical all-solid-state supercapacitor device was prepared by the following methods. One side of the prepared electrode was coated with conductive silver paste and connected to aluminum sheet, which was used as the current collector (Fig. S9 $\dagger$ ). Next the electrode was then immersed in the $\mathrm{PVA} / \mathrm{H}_{3} \mathrm{PO}_{4}$ electrolyte at least 30 minutes, after which time it was removed from the electrolyte and allowed to dry at $25{ }^{\circ} \mathrm{C}$ and under ventilation for 3 hours. Finally, two such electrodes were gently pressed together to obtain a sandwich structure as the all-solid-state supercapacitor device.

Cyclic voltammetry (CV) and galvanostatic charge-discharge (GCD) scanning tests were carried out in the range of 0 to $0.8 \mathrm{~V}$. Electrochemical impedance spectroscopy (EIS) was measured in a frequency range from $0.001 \mathrm{~Hz}$ to $100 \mathrm{kHz}$, at an amplitude of $0.005 \mathrm{~V}$ relative to the open circuit potential. For the threeelectrode tests, the areal specific capacitance $C_{\mathrm{s}}\left(\mathrm{F} \mathrm{cm}^{-2}\right)$ and the gravimetric specific capacitance $C_{\mathrm{g}}\left(\mathrm{F} \mathrm{g}^{-1}\right)$ were calculated as follows: $C_{\mathrm{s}}=\left(\int I \mathrm{~d} U\right) /(v S U)$ and $C_{\mathrm{g}}=(I \Delta t) /(m U)$, where $I(\mathrm{~A}), v(\mathrm{~V}$ $\left.\mathrm{s}^{-1}\right), S\left(\mathrm{~cm}^{2}\right), U(\mathrm{~V}), \Delta t(\mathrm{~s})$, and $m(\mathrm{~g})$, are the current, voltage scan rate, working area of the electrode, voltage window, discharge time, and total electrode weight, respectively. For the two-electrode tests, $C_{\mathrm{s}^{\prime}}=4\left(\int I \mathrm{~d} U\right) /(v S U)$ or $C_{\mathrm{s}^{\prime \prime}}=4(I \Delta t) /(S U)$, and $C_{\mathrm{g}^{\prime}}=4(I \Delta t) /$ $(m U)$, where $C_{\mathrm{s}^{\prime}}, C_{\mathrm{s}^{\prime \prime}}$, and $C_{\mathrm{g}^{\prime}}$ are the areal specific capacitances and gravimetric specific capacitance of the supercapacitor devices, respectively. ${ }^{29}$ The areal energy $E\left(\mathrm{~mW} \mathrm{~h} \mathrm{~cm}^{-2}\right)$ and the areal power $P\left(\mathrm{~mW} \mathrm{~cm}^{-2}\right)$ of the supercapacitor were obtained from the expressions: $E=1 / 4\left(U^{2} C_{\mathrm{s}^{\prime \prime}} / 2\right)$ and $P=E / \Delta t$, respectively.

\section{Results and discussion}

The nano-active materials must be pretreated appropriately to facilitate LbL assembly. The TEM images (Fig. S1†) show that PANi, CMWCNT, and GO have nanoparticle, tubular fiber, and typical nanosheet microstructures, respectively, all suitable for assembly. The average particle sizes of PANi, CMWCNT, and GO were 325, 210, and $315 \mathrm{~nm}$, respectively, and the corresponding zeta potentials were $43.6(\mathrm{pH} \sim 2.5),-44.3(\mathrm{pH} \sim 6.9)$, and $-41.2 \mathrm{mV}(\mathrm{pH} \sim 6.8)$, as measured by a laser particle size analyzer. These results indicated that the prepared nano-active material has the appropriate nano-particle size and sufficient surface charge for the subsequent LbL assembly experiments.

The most typical LbL assembly method involves alternating depositions of two or more components having different surface charges on the supporting substrate by using electrostatic adsorption and hydrogen bonding. In this study, CNF aerogels were used as nanofibrous scaffolds to deposit electrochemically active PANi nanoparticles, CMWCNT nanotubes, and GO nanosheets (Fig. 1a). Briefly, the PANi and CMWCNT (or GO) suspensions were alternately dripped onto the CNF aerogel, and it was ensured that the CNF aerogel had enough time for adsorption and deposition the nanomaterials after each liquid saturation. Then vacuum filtration was used to remove excess liquid. After being assembled only by PANi, the white CNF aerogel turns dark green in color, and finally turns black after being assembled many times through CMWCNT or GO (Fig. 1b). Under the driving force of electrostatic adsorption and hydrogen bonding, conductive polymer PANi with positive charge and inorganic electrochemically active materials GO and carboxylic CMWCNT with negative charge were alternately deposited on the CNF substrate with negative charge to obtain structurally ordered polymer-inorganic hybrid nanocomposite.

An aerogel made of CNF will undergo irreversible structural collapse after it encounters water because CNF is hydrophilic. Increasing the CNF concentration during the preparation of aerogels can increase the mechanical strength and density of aerogels to some extent. However, it can also convert the nanofibrous structure of the aerogels prepared with low concentrations of CNF into nanosheet structures, which reduces the specific surface area and permeability of the aerogel, and makes it unsuitable for the assembled matrix of the nano-active material. To solve this problem, we added tertbutanol to regulate the growth conditions of ice crystals and to inhibit the association between $\mathrm{CNF}$, which changes the microstructure of aerogels. ${ }^{30}$ BTCA was also added to obtain moderately cross-linked CNF aerogels with sufficient strength and negative charge. The thus-obtained CNF aerogel not only has a nanofiber-like microstructure, but also remains structurally intact after undergoing negative-pressure vacuum filtration several dozen times (Fig. S2a $\dagger$ ).

The microstructures of the CNF aerogel before and after assembly were analyzed by SEM. The SEM images (Fig. 2) show that even after BTCA micro-crosslinking, the CNF aerogel retains a fibrillar porous network structure (Fig. 2a), as described above, due to the influence of tert-butanol on ice crystal growth and CNF association. At high magnification, the surface of the CNF appears relatively smooth and the nanofibrils are intertwined with each other, with diameters of 50$200 \mathrm{~nm}$ (Fig. 2d). After the assembly of PANi and CMWCNT, the aerogel maintains a fibrillar network structure (Fig. 2b). Under high magnification, the surface of the nanofibrils exhibit 
(a)
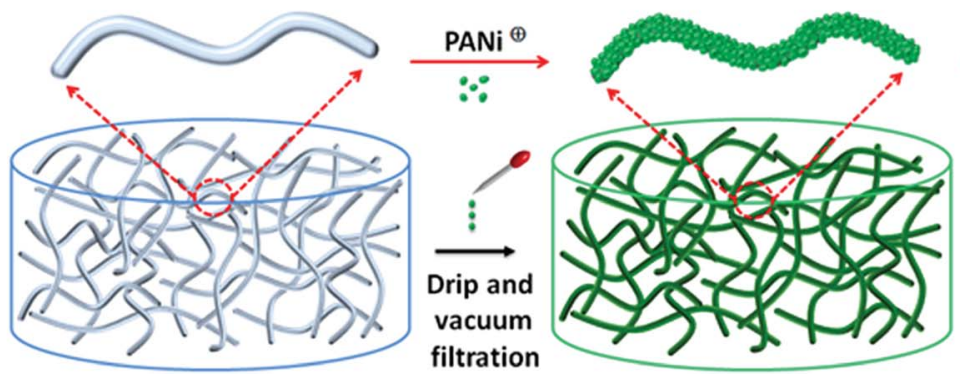

(b)

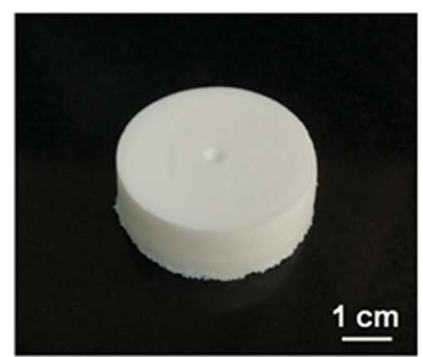

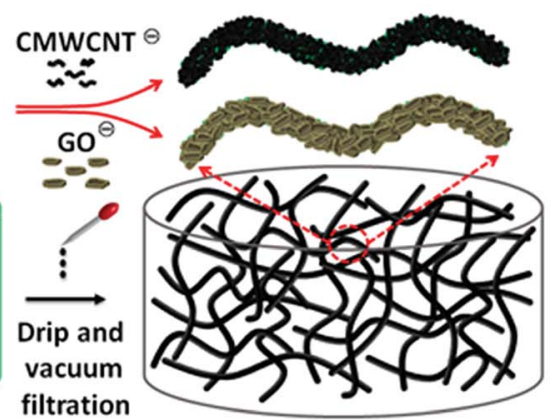

filtration

Fig. 1 (a) Schematic of the LbL assembly process to fabricate hierarchical PANi/CMWCNT and PANi/GO multilayers on the CNF nanofibrous network. (b) Representative photographs of the CNF aerogel, CNF aerogel following PANi assembly, and $\mathrm{CPC}_{10}$ aerogel from left to right. The appearance of $\mathrm{CPG}_{10}$ aerogel is similar to that of $\mathrm{CPC}_{10}$ aerogel.

a granular rough structure (Fig. 2e), indicating that PANi and CMWCNT are uniformly deposited on the CNF, and there is no obvious agglomeration. Similarly, after the assembly of PANi and GO, the aerogel maintains a fibrillar network structure (Fig. 2c), and the nanofibril surface also has a granular rough structure (Fig. 2f). Slightly different from the $\mathrm{CPC}_{10}$ aerogel, the fibrillar nature of the $\mathrm{CPG}_{10}$ aerogel decreased a little, and more nanofilm structure appeared. This may be due to the larger diameter of the GO used herein, resulting in nanofibrils having small diameter, to be encapsulated by the GO layer, forming a nanofilm structure.

We also use TEM to analyze the microstructures of CNF aerogel before and after its assembly (Fig. 3). Before assembly, the surface of nanofibrils formed by CNF association is very smooth (Fig. 3a and S3a $\dagger$ ). After assembly, PANi and CMWCNTs adhered to the nanofibril surface to form a rough bundle-like structure (Fig. 3b and S3b †), while PANi and GO formed a rough wrinkled structure (Fig. $3 \mathrm{c}$ and S3c†). Local
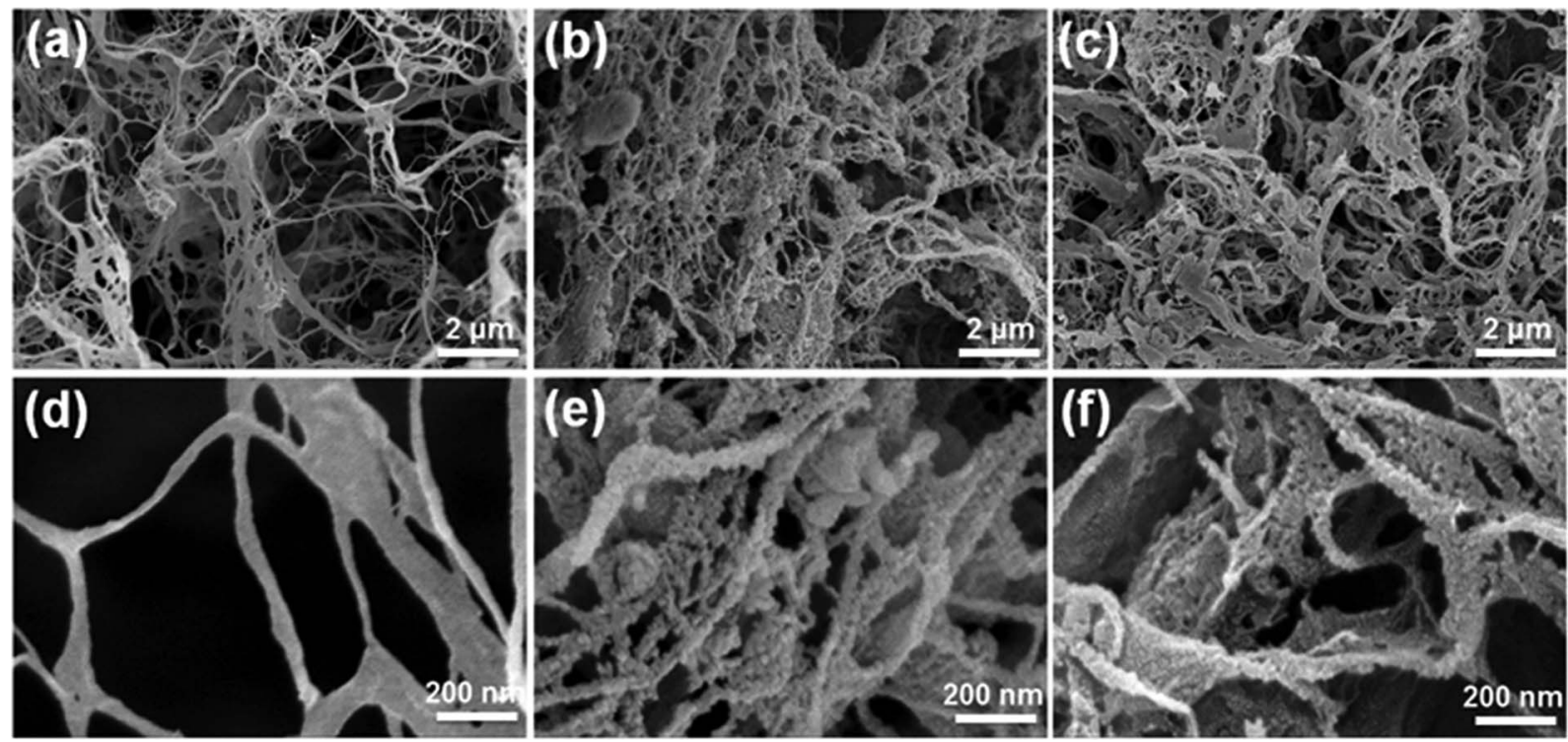

Fig. 2 SEM images of nanofibrous networks microstructures of different aerogels: (a and d) CNF aerogel, (b and e) CPC 10 aerogel, and (c and f) $\mathrm{CPG}_{10}$ aerogel at different magnifications. 

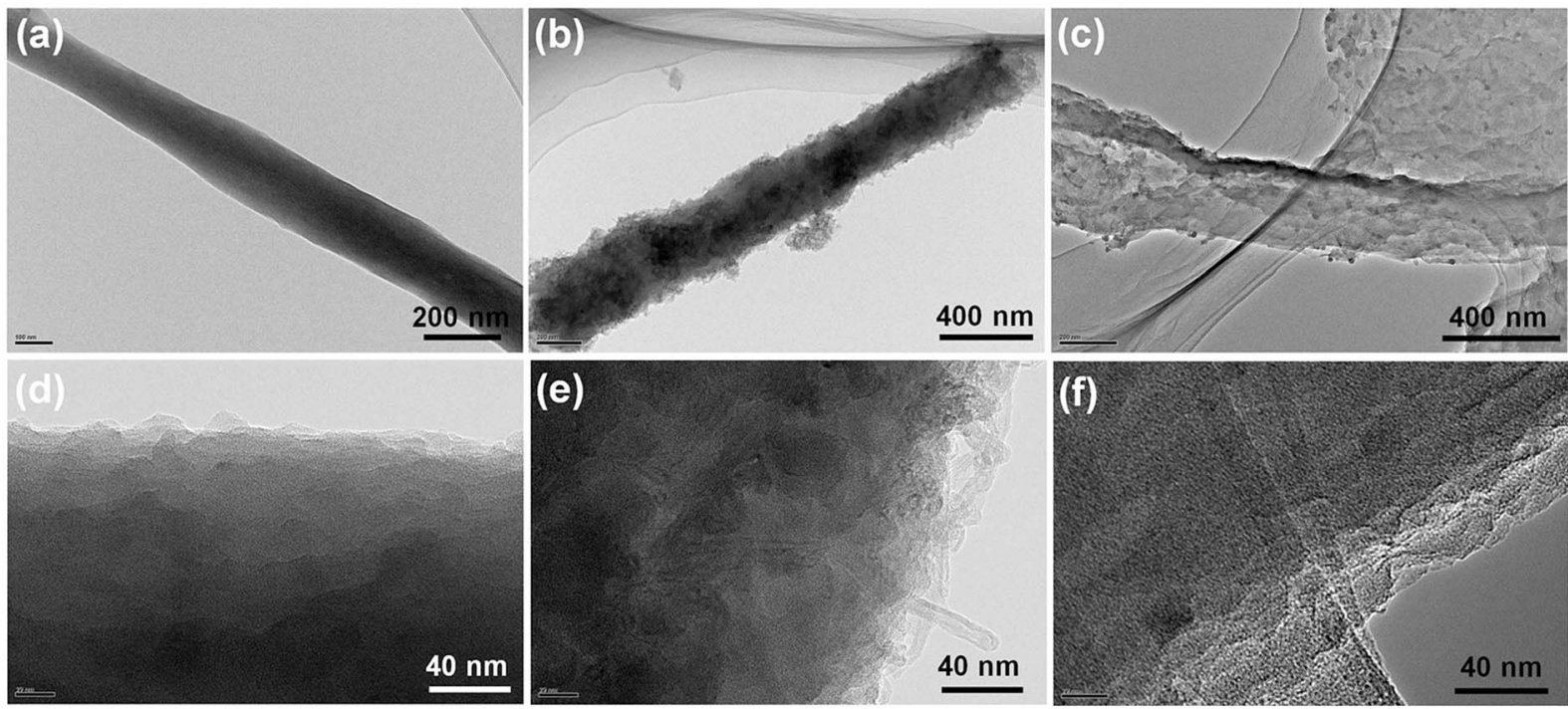

Fig. 3 TEM images of (a) pure CNF nanofibrils, (b) $P C_{10}$, and (c) $P G_{10}$ assembled on CNF nanofibril. (d) Locally enlarged TEM image of only PANi assembled on CNF nanofibril. Locally enlarged TEM image of (e) $\mathrm{PC}_{10}$ and (f) $\mathrm{PG}_{10}$ assembled on CNF nanofibrils.

amplification reveals that after PANi assembly alone, PANi was uniformly deposited on the nanofibril surface to form a distinct nanoparticle structure (Fig. 3d). After 10 rounds of assembly, PANi and CMWCNT were interspersed with each other on the nanofibril surface, and the nanotube structure of the CMWCNT was clearly visible on the outermost layer (Fig. 3e). PANi and GO were stacked one after another on the nanofibril surface, and in the outermost layer, the wrinkled lamellar structure formed by GO was clearly seen (Fig. 3f). The SEM and TEM analyses revealed that the nano-active material was successfully assembled on the nanofibrils inside the CNF aerogel.

Generally, the higher the specific surface area of the electrode material, the larger is the contact area between the electrode and the electrolyte, leading to better electrochemical performance. ${ }^{31}$ The specific surface area and pore structure of CNF aerogels before and after assembly were analyzed by the nitrogen adsorption method (Fig. 4a and S4a $\dagger$ ). The BET specific surface area of CNF aerogel before assembly can reach $63 \pm 1 \mathrm{~m}^{2} \mathrm{~g}^{-1}$ and the pore volume can reach $0.137 \mathrm{~cm}^{3} \mathrm{~g}^{-1}$. After assembly, the specific surface areas of the $\mathrm{CPC}_{10}$ and $\mathrm{CPG}_{10}$ aerogels improved to $183 \pm 1$ and $86 \pm 1 \mathrm{~m}^{2} \mathrm{~g}^{-1}$, respectively, and their corresponding pore volumes improved to 0.245 and $0.471 \mathrm{~cm}^{3} \mathrm{~g}^{-1}$. The $\mathrm{CPC}_{10}$ aerogel has higher specific surface area than the $\mathrm{CPG}_{10}$ aerogel, but the pore volume is slightly smaller, indicating that the $\mathrm{CPC}_{10}$ aerogel has more micropores, while the $\mathrm{CPG}_{10}$ aerogel has more mesopores and macropores. This is consistent with the results of the microstructure analyses.

The physicochemical structures of CNF aerogel before and after its assembly were studied by XPS, FTIR, Raman spectroscopy, and XRD. The composition and proportion of surface elements of the three aerogels changed significantly after assembly (Fig. S4b $\dagger$ ). The $\mathrm{C} / \mathrm{O}$ ratios of the $\mathrm{CNF}, \mathrm{CPC}_{10}$, and $\mathrm{CPG}_{10}$ aerogels are 1.01, 3.18 and 1.89, respectively (Fig. S4c $\dagger$ ). This change is also directly reflected by the C1s spectra of the three aerogels. Compared with the $\mathrm{C}-\mathrm{O}$ peak intensity of the $\mathrm{CNF}$ aerogel at $286.2 \mathrm{eV}$, the $\mathrm{C}-\mathrm{O}$ peaks at 286.1 and $286.8 \mathrm{eV}$ for the $\mathrm{CPC}_{10}$ and $\mathrm{CPG}_{10}$ aerogels, respectively, decreased significantly in intensity. This decrease is in relation to the $\mathrm{C}=\mathrm{C} / \mathrm{C}-\mathrm{C}$ peak intensity at the correction position of $284.8 \mathrm{eV}$. Compared with the C1s peaks of the CNF aerogel, extra peaks at 285.1 and $285.4 \mathrm{eV}$ are observed for $\mathrm{CPC}_{10}$ (Fig. 4b) and $\mathrm{CPG}_{10}$ (Fig. 4c) aerogels, respectively, which should be ascribed to the $\mathrm{C}-\mathrm{N} / \mathrm{C}=$ $\mathrm{N}$ peak. ${ }^{32}$ Because there are many carboxyl $(-\mathrm{COOH})$ groups on CMWCNT and GO, which can form N-O-C linkage through the amino functional groups of PANi. ${ }^{33}$ We also show the N1s XPS spectra of PANi, in which the peaks at 399.6 and $400.2 \mathrm{eV}$ are assigned to $-\mathrm{NH}-$ and $-\mathrm{NH}^{+}$- groups, while the one at $401.7 \mathrm{eV}$ is ascribed to the $=\mathrm{NH}^{+}$- groups (Fig. S4e and $\mathrm{f}_{\dagger}^{+}$). The FTIR spectra of CNF aerogel before and after its assembly (Fig. 4d) show the changes in functional groups. After assembly, new peaks appeared for both $\mathrm{CPC}_{10}$ and $\mathrm{CPG}_{10}$ aerogels, corresponding to the $\mathrm{N}=\mathrm{Q}=\mathrm{N}$ stretching vibrations at $1587 \mathrm{~cm}^{-1}$, $\mathrm{N}-\mathrm{B}-\mathrm{N}$ stretching vibrations at $1501 \mathrm{~cm}^{-1}$ (where $\mathrm{B}$ and $\mathrm{Q}$ represent the benzenoid and quinoid moieties), and $\mathrm{C}-\mathrm{N}$ stretching vibrations at $1313 \mathrm{~cm}^{-1}$, with aromatic conjugation that are characteristic of PANi. ${ }^{34}$ Raman spectroscopy was also used to obtain structural information about the nano-active materials assembled inside the CNF aerogel. The Raman spectra of both $\mathrm{CPC}_{10}$ and $\mathrm{CPG}_{10}$ aerogels after assembly show five peaks: the peaks at 1161 and $1218 \mathrm{~cm}^{-1}$ are ascribed to the $\mathrm{C}-\mathrm{H}$ bending of the $\mathrm{Q}$ and $\mathrm{B}$ ring vibrations, the peaks at $1465 \mathrm{~cm}^{-1}$ are attributed to the $\mathrm{C}=\mathrm{N}$ bending, while those at 1328 and $1591 \mathrm{~cm}^{-1}$ are assigned to the $\mathrm{D}$ and $\mathrm{G}$ singles of the of graphitic fragments of CMWCNTs and GO, respectively (Fig. 4e). ${ }^{32,33}$ Fig. $4 f$ shows the XRD patterns of the three aerogels. The diffraction peaks at $2 \theta=14.8^{\circ}(101), 21.6^{\circ}(002)$, and $33.7^{\circ}(040)$, correspond to the cellulose I crystalline structure and completely masked the peaks of the nano-active materials. Therefore, BET surface area, and the XPS, FTIR, XRD, and 

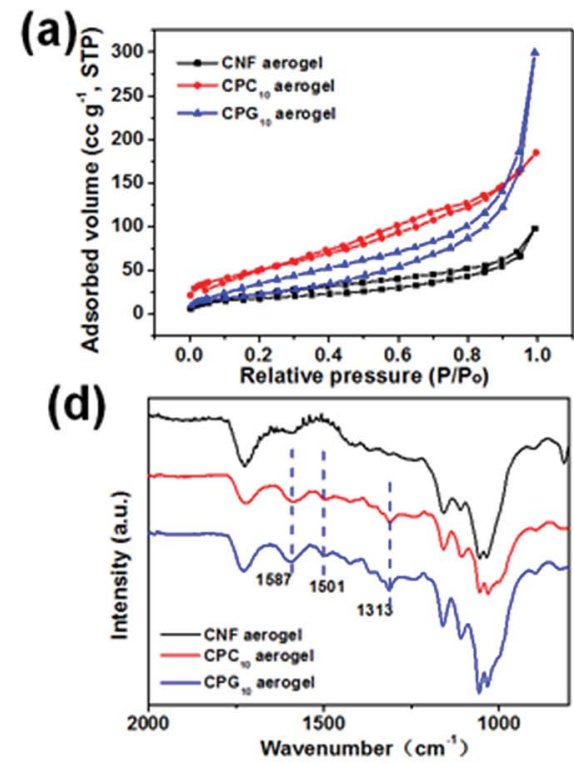
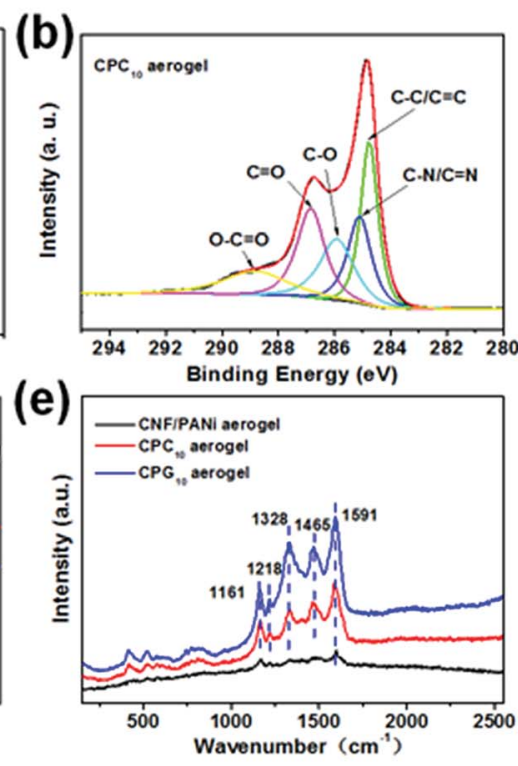
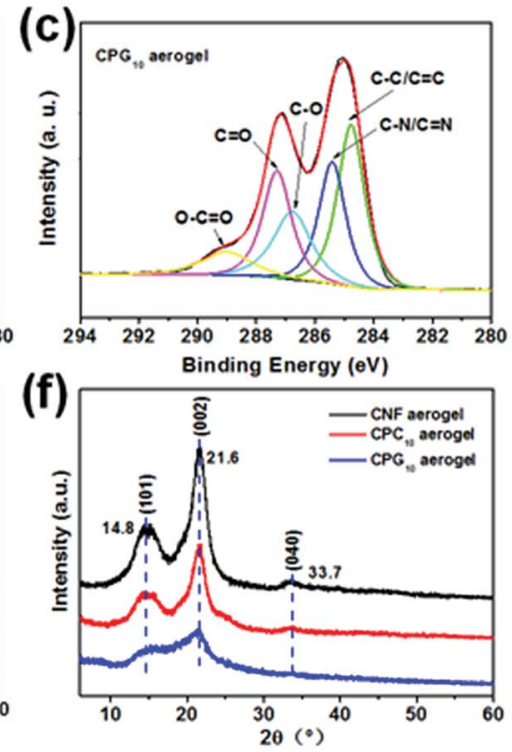

Fig. 4 (a) Nitrogen adsorption/desorption isotherms for the $C N F, C P C_{10}$, and $C_{10} G_{10}$ aerogels. High-resolution XPS $C 1 s$ spectra of (b) $C P C_{10}$ and (c) $C P G_{10}$ aerogels. (d) FTIR spectra and (f) XRD pattern of the CNF, CPC 10 , and $C P G_{10}$ aerogels. (e) Raman spectra of the CNF/PANi, CPC 10 , and $\mathrm{CPG}_{10}$ aerogels. CNF/PANi aerogels means that only PANi is assembled on CNF nanofibril.

Raman spectra confirmed successful LbL assembly of nanoactive materials into CNF aerogels.

To verify that the supercapacitor electrodes prepared by assembling nano-active materials with CNF aerogels as the skeleton have better electrochemical performance than the electrodes assembled by the traditional film, the electrochemical properties of the as-prepared $\mathrm{CPC}_{10}$ and $\mathrm{CPR}_{10}$ supercapacitor electrodes were first examined by a standard three-electrode system in $1 \mathrm{M} \mathrm{H}_{2} \mathrm{SO}_{4}$ aqueous solution. Then, a two-electrode system was used to further analyze the symmetric supercapacitor devices prepared by $\mathrm{CPC}_{10}$ and $\mathrm{CPR}_{10}$ with $\mathrm{PVA} / \mathrm{H}_{3} \mathrm{PO}_{4}$ gel as the electrolyte. The influence of $\mathrm{LbL}$ assembly cycles on the electrochemical performance of the supercapacitor electrodes was also analyzed.

Fig. $5 \mathrm{a}$ and $\mathrm{b}$ show the typical CV curves of the $\mathrm{CPC}_{10}$ and $\mathrm{CPR}_{10}$ electrodes, respectively, at scan rates varying from 2 to $200 \mathrm{mV} \mathrm{s}^{-1}$. Both show obvious redox peaks, which mainly correspond to the leucoemeraldine/emeraldine and emeraldine/pernigraniline redox reactions of PANi. ${ }^{32}$ At the same scan rate, the redox peaks of $\mathrm{CPC}_{10}$ are stronger than those of $\mathrm{CPR}_{10}$ (Fig. S5a $\dagger$ ) because $\mathrm{CPC}_{10}$ has a microporous structure and higher specific surface area than $\mathrm{CPR}_{10}$, which is beneficial for ion diffusion. ${ }^{35} \mathrm{An}$ increase in the scan rate causes the anodic and cathodic peaks to shift to higher and lower potentials, respectively, due to the internal resistance of the electrode. The relationship between maximum current density and scan rate for the two electrodes is displayed in Fig. 5c. Notably, maximum current densities for both electrodes increased nonlinearly with scan rate. According to the power law equation $I a v^{b}$, where $I$ and $v$ are current density and scan rate, respectively, and adjustable parameters $a$ and $b$ can be obtained from the intercept and slope of a linear plot of $\log I v s$. $\log v$, respectively. ${ }^{32,36}$ When the $b$ value is 0.5 , it is an ideal diffusion-controlled process. When the $b$ value is 1 , it is an ideal non-diffusion controlled process. When the $b$ value is between the two, it is a complex control process. The $b$ values of the $\mathrm{CPC}_{10}$ and $\mathrm{CPR}_{10}$ electrodes reach 0.51 and 0.54 in anodic scans (Fig. S5b†), implying that both electrodes operate their redox processes through a complex control mechanisms, respectively. ${ }^{32,36}$ The GCD curves of the two electrodes also show obvious pseudopotential capacitance (Fig. $5 \mathrm{~d}$ and e). At the same current density, $\mathrm{CPC}_{10}$ has longer charge and discharge times than $\mathrm{CPR}_{10}$. The IR drops of $\mathrm{CPC}_{10}$ and $\mathrm{CPR}_{10}$ electrodes at different current densities in a three-electrode test were $\sim 0.20 \mathrm{~V}$ and $\sim 0.24 \mathrm{~V}$, respectively (Fig. $5 \mathrm{~d}$ and e). The Nyquist plots of the $\mathrm{CPC}_{10}$ and $\mathrm{CPR}_{10}$ electrodes, obtained using EIS at the open circuit potential are shown in Fig. 5 f. The equivalent series resistance (ESR) of the two electrodes is nearly the same (13.67 $\Omega$ for $\mathrm{CPC}_{10}$ and $12.12 \Omega$ for $\mathrm{CPR}_{10}$ ), but the charge transfer resistance $\left(R_{\mathrm{ct}}\right)$ of $\mathrm{CPC}_{10}(62.82 \Omega)$ is much smaller than that of $\mathrm{CPR}_{10}(140.85 \Omega)$, indicating that $\mathrm{CPC}_{10}$ has better ion accessibility in the electrolyte. Bode plots of the $\mathrm{CPC}_{10}$ and $\mathrm{CPR}_{10}$ electrodes also show that the impedance $Z$ is relatively small at high frequencies; as the frequency decreases, $Z$ sharply increases and becomes less frequency dependent (Fig. S7a $\uparrow$ ). The phase angles of the two electrodes increase rapidly with the increase of the frequency to the maximum values of $26^{\circ}\left(\mathrm{CPC}_{10}\right)$ and $31^{\circ}\left(\mathrm{CPR}_{10}\right)$, and then drop rapidly and eventually drop to about 2 (Fig. S7b †).

Good accessible capability of ions in the electrolyte renders higher capacitance performance to $\mathrm{CPC}_{10}$ (Fig. $5 \mathrm{~g}$ ) in terms of the areal specific capacitance calculated from the $\mathrm{CV}$ curves at different scan rates and the gravimetric specific capacitance calculated from the GCD curves at different current densities (Fig. $5 \mathrm{~h}$ ). The $\mathrm{CPC}_{10}$ showed a very high areal specific capacitance of $1.21 \mathrm{~F} \mathrm{~cm}^{-2}$ at a scan rate of $1 \mathrm{mV} \mathrm{s}^{-1}$, whereas $\mathrm{CPR}_{10}$ 
(a)
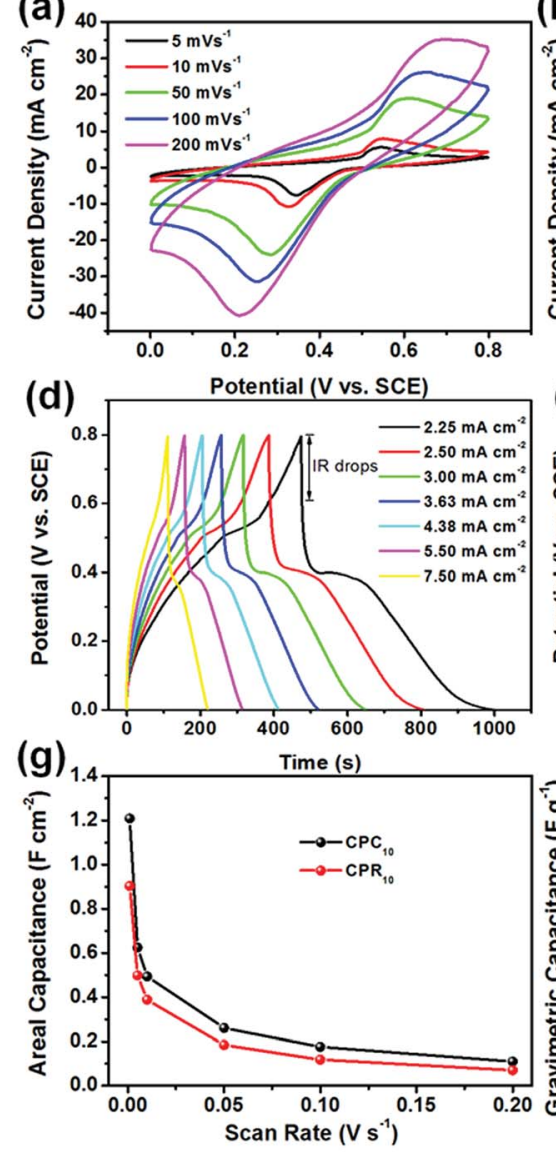
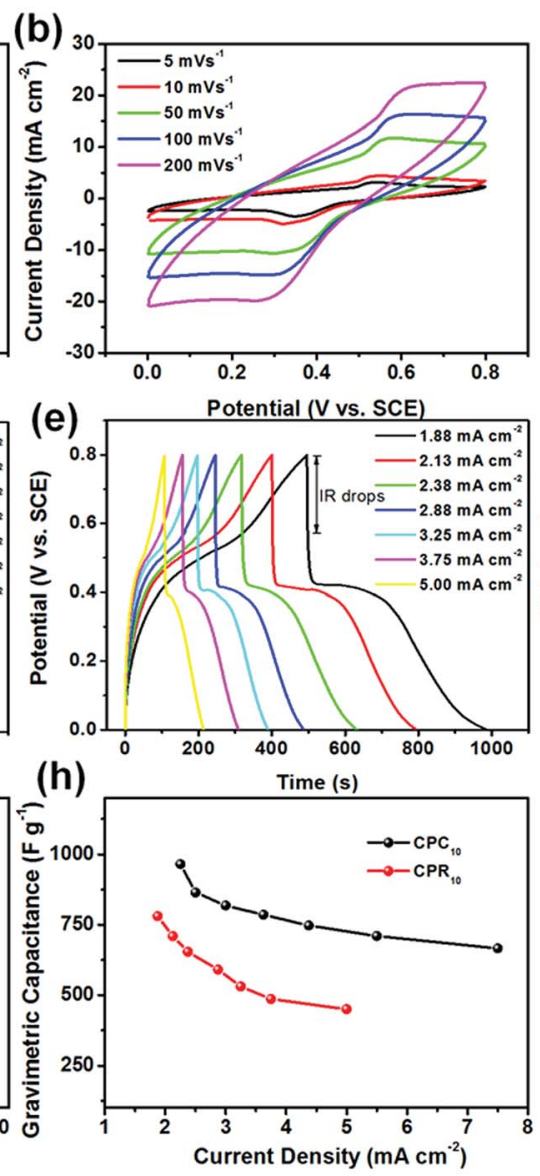

(c)
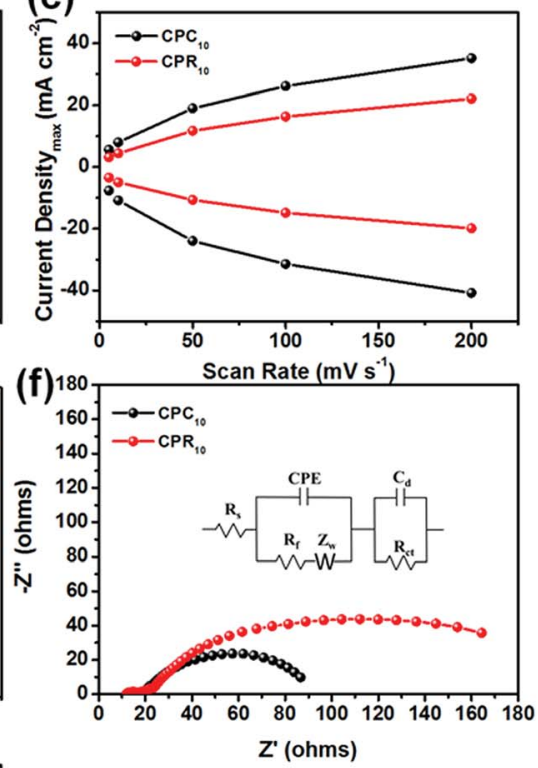

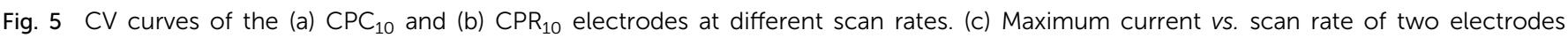

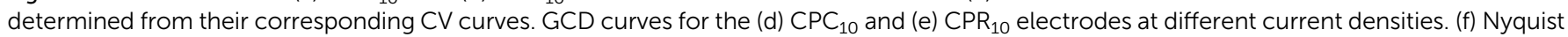

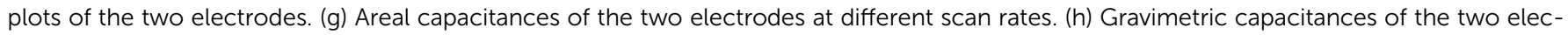
trodes at different current densities. All data were obtained under three-electrode testing conditions in $1 \mathrm{M} \mathrm{H}_{2} \mathrm{SO}_{4}$.

had an areal specific capacitance of only $0.90 \mathrm{~F} \mathrm{~cm}^{-2}$ under the same conditions. The $\mathrm{CPC}_{10}$ also has a larger gravimetric specific capacitance $\left(965.80 \mathrm{~F} \mathrm{~g}^{-1}\right.$ at a current density of 2.25 $\left.\mathrm{mA} \mathrm{cm}{ }^{-2}\right)$ than that of $\mathrm{CPR}_{10}\left(780.64 \mathrm{~F} \mathrm{~g}^{-1}\right.$ at a current density of $1.875 \mathrm{~mA} \mathrm{~cm}{ }^{-2}$ ). Moreover, these capacitance properties achieved by the LbL assembly the nanocomposite active materials within the CNF aerogels were better than those of previously reported PANi/RGO assemblies, ${ }^{37}$ PANi/RGO LbL films, ${ }^{38}$ and PANi/RGO LbL hollow spheres ${ }^{39}$ under the same test conditions. These capacitance properties further confirm that PANi, CMWCNT, and RGO, LbL assembled on the nanofibrils inside the porous CNF aerogel, can achieve outstanding electrochemical performance.

To verify the performance of the LbL-assembled electrode in practical applications, an all-solid symmetric supercapacitor was prepared using $\mathrm{CPC}_{n}$ and $\mathrm{CPR}_{n}$ as electrode materials with $\mathrm{PVA} / \mathrm{H}_{3} \mathrm{PO}_{4}$ gel as the electrolyte. We first investigated the effect of the number of LbL assembly cycles on the electrochemical performance of the supercapacitor electrode (Fig. 6). Fig. 6a and b show the CV curves of the two supercapacitors obtained at a scan rate of $50 \mathrm{mV} \mathrm{s}^{-1}$ for different LbL assembly cycles. With increasing number of LbL assembly cycles, the CV curve becomes more regular, and the integral area of the curve and the areal specific capacitance calculated from the CV curve increase gradually. For the same LbL assembly cycle, the areal specific capacitance of $\mathrm{CPC}_{n}$ is greater than that of $\mathrm{CPR}_{n}$, and presents an approximately linear relationship with the number of LbL assembly cycles (Fig. 6c). Similar phenomena also appear on the GCD curve (Fig. $6 \mathrm{~d}$ and e). At a current density of $1.0 \mathrm{~mA}$ $\mathrm{cm}^{-2}$, with increasing number of LbL assembly cycles, the GCD curve approaches a symmetric triangle, and the chargedischarge time and gravimetric specific capacitance obtained according to the GCD curve increase (Fig. 6f). This is because the mass loading of the nano-active material on the CNF aerogel increases gradually with increasing number of LbL assembly cycles (Fig. S6a $\dagger$ ), resulting in an increase in the degree of denser packing of the nano-active material, forming more continuous conductive networks inside the electrode (Fig. S6b $\dagger$ ), thus providing more interrelated pathways for electron transport, and improving electrochemical performance.

The detailed information of the as-prepared all-solid symmetric supercapacitors with electrodes prepared by $10 \mathrm{LbL}$ assembly cycles is investigated by CV, GCD, and EIS in Fig. 7. 
(a) 6
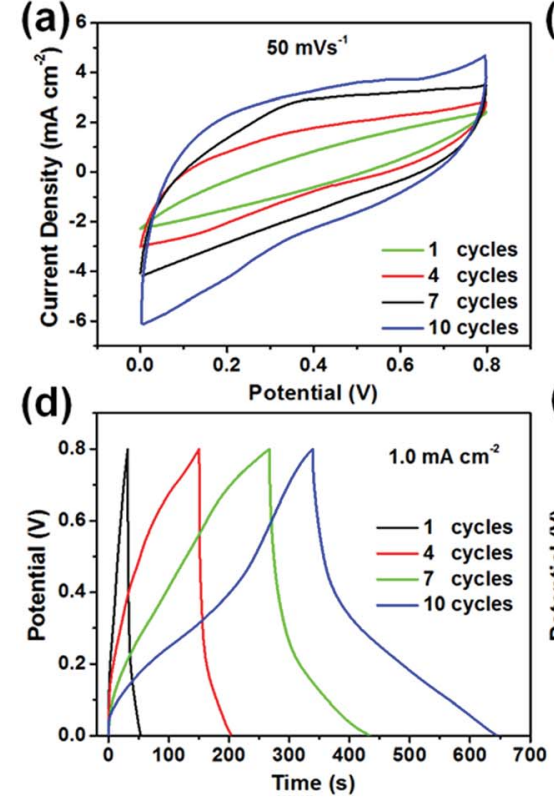

(b)

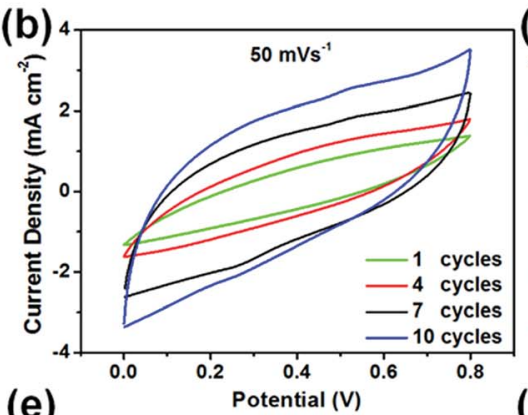

(e)

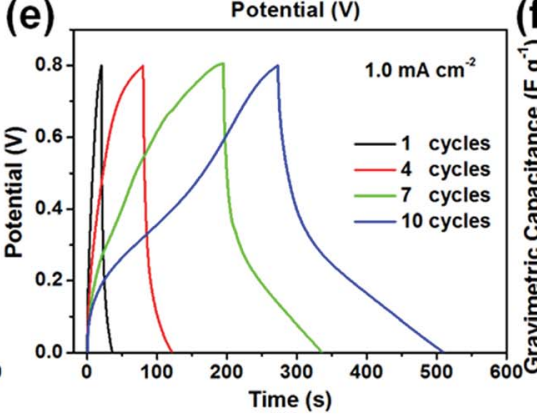

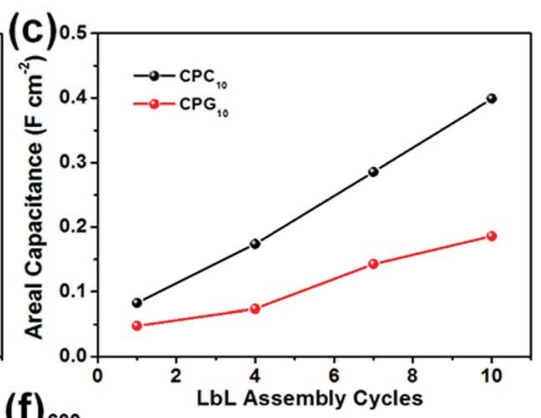

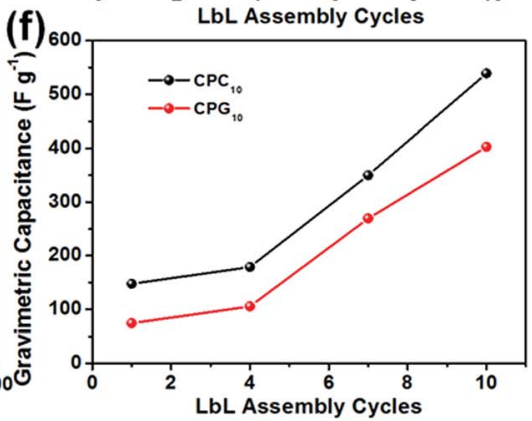

Fig. $6 \mathrm{CV}$ curves of the (a) $\mathrm{CPC}_{n}$ and (b) $\mathrm{CPR}_{n}$ electrodes at different LbL assembly cycles. (c) Areal specific capacitance of the two electrodes at different LbL assembly cycles. GCD curves of (d) $C P C_{n}$ and (e) $C_{2} R_{n}$ electrodes at different LbL assembly cycles. (f) Gravimetric specific capacitance of the two electrodes at different LbL assembly cycles. All data were obtained under two-electrode testing conditions with PVA/ $\mathrm{H}_{3} \mathrm{PO}_{4}$ gel electrolyte.

The $\mathrm{CV}$ curves of the $\mathrm{CPC}_{10}$ and $\mathrm{CPR}_{10}$ supercapacitors obtained at different scan rates (Fig. 7a and d, respectively) show almost rectangular shapes and can be maintained without any obvious distortion at $200 \mathrm{mV} \mathrm{s}^{-1}$, especially for $\mathrm{CPC}_{10}$, illustrating good charge transfer performance inside the supercapacitor. The GCD curves of both $\mathrm{CPC}_{10}$ and $\mathrm{CPR}_{10}$ supercapacitors at different current densities (Fig. 7b and e) show approximately symmetric triangles, indicating good charge and discharge performance for both supercapacitors; the GCD curve is especially regular for $\mathrm{CPC}_{10}$. The IR drops of $\mathrm{CPC}_{10}$ and $\mathrm{CPR}_{10}$ supercapacitors at different current densities in a two-electrode test were $\sim 0.05 \mathrm{~V}$ and $\sim 0.06 \mathrm{~V}$, respectively. The IR drops of the
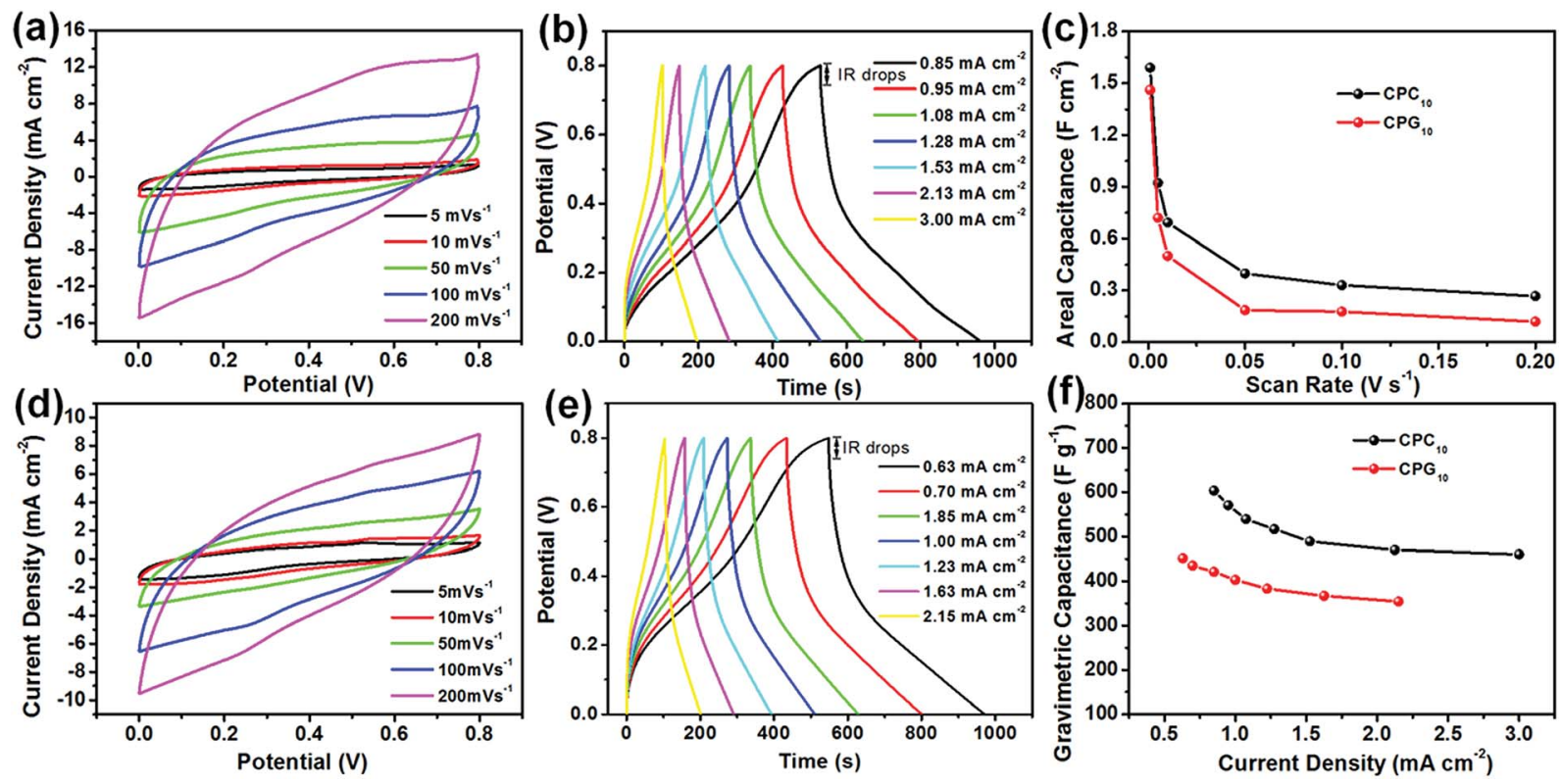

Fig. 7 CV curves of the (a) $C P C_{10}$ and (d) $C P R_{10}$ electrodes at different scan rates. (c) Areal capacitances of the two electrodes at different scan rates. GCD curves for the (b) $C P C_{10}$ and (e) $C P R_{10}$ electrodes at different current densities. (f) Gravimetric capacitances of the two electrodes at different current densities. All data were obtained under two-electrode testing conditions with $\mathrm{PVA} / \mathrm{H}_{3} \mathrm{PO}_{4}$ gel electrolyte. 
symmetric devices were smaller than that of electrode samples. This was because in the three-electrode test, the electrode samples were swelling slowly due to hydrophilic properties of nanocellulose during testing, resulting in an increase in the distance between the conductive networks inside the electrodes and a decrease of interrelated pathways for electron transport, which decreased the electrical conductivities and then increased IR drops. ${ }^{22,40}$ The electrodes of symmetric devices almost maintained the same volume in $\mathrm{PVA} / \mathrm{H}_{3} \mathrm{PO}_{4}$ gel electrolyte during testing. Thus the electrodes of symmetric devices showed smaller IR drops. From the Nyquist plot (Fig. S7c $\dagger$ ), $\mathrm{CPC}_{10}$ and $\mathrm{CPR}_{10}$ have ESR values of $15.80 \Omega$ and $23.05 \Omega$, respectively, indicating that $\mathrm{CPC}_{10}$ has a smaller internal resistance than $\mathrm{CPR}_{10}$. The $R_{\mathrm{ct}}$ of the $\mathrm{CPC}_{10}(2.01 \Omega)$ is also lower than that of the $\mathrm{CPR}_{10}(2.29 \Omega)$. Bode plots of the symmetric devices also show that the impedance $Z$ sharply decreases as the frequency increases and then levels off gradually (Fig S7d $\dagger$ ). The Bode plot between phase angles versus frequency (Fig. S7e $\dagger$ ) shows a similar trend. The phase angles approach to $70^{\circ}$ $\left(\mathrm{CPC}_{10}\right)$ and $63^{\circ}\left(\mathrm{CPR}_{10}\right)$ at low frequencies; as the frequency increases, both phase angles sharply decrease and approach zero (Fig. S7e $\dagger$ ). The $\mathrm{CPC}_{10}$ supercapacitor shows relatively better electrochemical performance than the $\mathrm{CPR}_{10}$ supercapacitor because the $\mathrm{CPC}_{10}$ aerogel has better fibrillar network structure and higher specific surface area, facilitating ion diffusion and electron transport, consistent with the above analysis results.

For comparison, from the $\mathrm{CV}$ curves at $1 \mathrm{mV} \mathrm{s}^{-1}$, the areal specific capacitances were calculated to be 1.59 and $1.46 \mathrm{~F} \mathrm{~cm}^{-2}$ for the $\mathrm{CPC}_{10}$ and $\mathrm{CPR}_{10}$ electrodes, respectively (Fig. 7c). The areal specific capacitance of the LbL assembled supercapacitor electrode is higher than those of other electrodes prepared by other methods using similar electroactive materials, such as PANi/RGO assembled CNF-based film electrode, ${ }^{41}$ carbon nanotube/PANi hydrogel film electrodes, ${ }^{42}$ and 3D porous RGO/ PANi composites. ${ }^{43}$ Moreover, the highest gravimetric specific capacitance values were $603.39 \mathrm{~F} \mathrm{~g}^{-1}$ at a current density of 0.85 $\mathrm{mA} \mathrm{cm}{ }^{-2}$ and $451.57 \mathrm{~F} \mathrm{~g}^{-1}$ at a current density of $0.63 \mathrm{~mA} \mathrm{~cm}^{-2}$ for $\mathrm{CPC}_{10}$ and $\mathrm{CPR}_{10}$ electrodes, respectively. Both supercapacitor electrodes exhibited slight declines in rate performance, with $76.29 \%$ capacitance retention for $\mathrm{CPC}_{10}$ when the current density was increased from 0.85 to $3.0 \mathrm{~mA} \mathrm{~cm} \mathrm{~cm}^{-2}$, and $78.42 \%$ capacitance retention for $\mathrm{CPR}_{10}$ when the current density was increased from 0.63 to $2.15 \mathrm{~mA} \mathrm{~cm}^{-2}$.
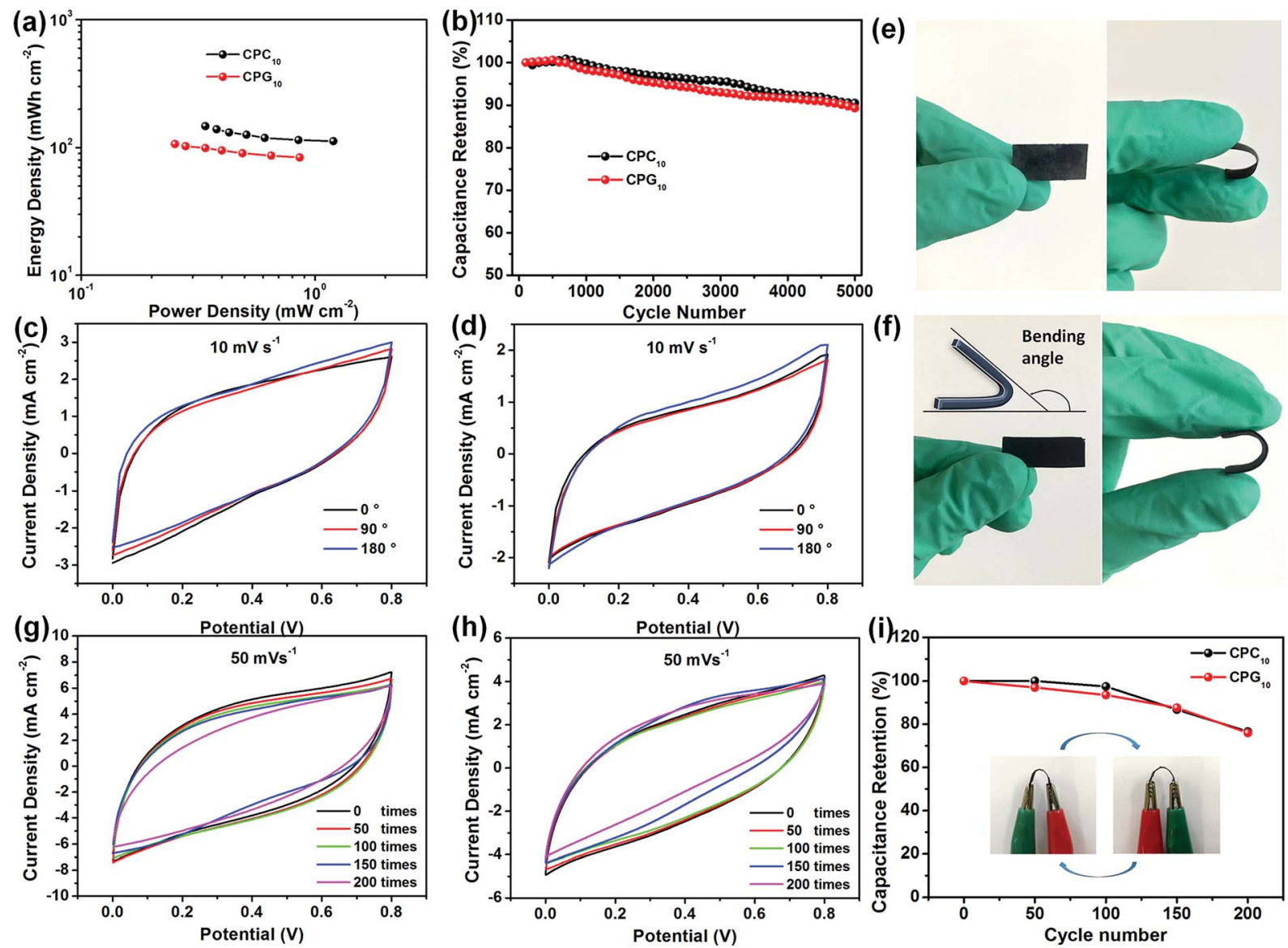

Fig. 8 (a) Ragone plots of power density vs. energy density for the two assembled supercapacitors. (b) Cycling stabilities of the two assembled supercapacitors. CV curves of (c) $C P C_{10}$ and (d) $C P R_{10}$ electrodes at different bending angles. Representative photographs of (e) $C P C_{10}$ and (f) $\mathrm{CPR}_{10}$ electrodes in normal and bent states. CV curves of $(\mathrm{g}) \mathrm{CPC}_{10}$ and (h) $\mathrm{CPR}_{10}$ electrodes after folding 200 times at a scan rate of $50 \mathrm{mV} \mathrm{s}^{-1}$. (i) Stability of electrode capacitance after 200 bending cycles according to CV curves in (g) and (h). Illustration is the schematic diagram of the electrode's bending state. All data were obtained under two-electrode testing conditions with $\mathrm{PVA} / \mathrm{H}_{3} \mathrm{PO}_{4}$ gel electrolyte. 
The superior energy storage performance and outstanding rate capabilities of the LbL-assembled nanocomposite electrodes can be attributed to the unique multilayer configuration and hybrid nanoarchitectures. The LbL-assembled hybrid structures created by PANi/CMWCNT and PANi/RGO on the surface of CNF nanofibrils creates an interconnected network, which shortens the ion migration and diffusion paths, thus promoting rapid ion intercalation/de-intercalation during the rapid redox process. Furthermore, the high-specific-area 3D fibrous networks of the CNF aerogels not only acts as the scaffold for nano-active material, but also facilitates permeability of the aqueous electrolyte into the electrode because of the natural hydrophilic properties of CNF. ${ }^{26}$

To further study the electrochemical performance of the supercapacitors in practical applications, the power density and energy density of the prepared all-solid supercapacitors were calculated from the GCD curve. The two types of supercapacitors exhibit a clear correspondence between power output and energy density (Fig. 8a). The $\mathrm{CPC}_{10}$ supercapacitor exhibits a maximum areal specific energy of $147.23 \mathrm{~mW} \mathrm{~h} \mathrm{~cm}^{-2}$ at an areal specific power of $0.34 \mathrm{~mW} \mathrm{~cm}^{-2}$ and retains an areal specific energy of $112.32 \mathrm{~mW} \mathrm{~h} \mathrm{~cm}{ }^{-2}$ at a higher areal specific power of $1.20 \mathrm{~mW} \mathrm{~cm}{ }^{-2}$. The performance of the $\mathrm{CPR}_{10}$ supercapacitor is slightly lower than that of $\mathrm{CPC}_{10}$, and the former shows an areal specific energy of $106.57 \mathrm{~mW} \mathrm{~h} \mathrm{~cm}^{-2}$ at an areal specific power of $0.25 \mathrm{~mW} \mathrm{~cm}{ }^{-2}$. Gravimetric or volumetric energy and power of $\mathrm{CPC}_{10}$ and $\mathrm{CPR}_{10}$ supercapacitor are presented in Fig. S11. $\dagger$ The $\mathrm{CPC}_{10}$ has maximum energy density of $48429 \mathrm{~mW} \mathrm{~h} \mathrm{~g}^{-1}\left(956 \mathrm{~mW} \mathrm{~h} \mathrm{~cm}{ }^{-3}\right)$ at a power density of 111 $\mathrm{mW} \mathrm{g}{ }^{-1}\left(2.21 \mathrm{~mW} \mathrm{~cm}{ }^{-3}\right)$, and the $\mathrm{CPR}_{10}$ has maximum energy density of $36248 \mathrm{~mW} \mathrm{~h} \mathrm{~g}^{-1}\left(745 \mathrm{~mW} \mathrm{~h} \mathrm{~cm}^{-3}\right)$ at a power density of $85 \mathrm{~mW} \mathrm{~g}^{-1}\left(1.76 \mathrm{~mW} \mathrm{~cm}^{-3}\right)$.

Cyclic stability tests of the two supercapacitors were conducted by repeating the $\mathrm{CV}$ cycles at a scan rate of $10 \mathrm{mV} \mathrm{s}^{-1}$ (Fig. $8 \mathrm{~b}$ and S8 $\dagger$ ). After $5000 \mathrm{CV}$ cycles, the $\mathrm{CPC}_{10}$ and $\mathrm{CPR}_{10}$ supercapacitors retained about $90.47 \%$ and $89.33 \%$ capacitance, respectively. The two types of supercapacitors also showed coulombic efficiency of $\sim 85 \%$ throughout the various current densities (Fig. S10a†). The excellent electrochemical durability reflected the reversibility of the charge storage reaction of the prepared all-solid supercapacitor with stable adhesion of nano-active material on the CNF aerogels. Both supercapacitor electrodes have good flexibilities due to their nanocellulose skeletons (Fig. 8e and f). To evaluate their potential applications in flexible and wearable electronic devices, the electrochemical performance of the two supercapacitors at different bending angles was characterized. The $\mathrm{CV}$ curves at a scan rate of $10 \mathrm{mV} \mathrm{s}^{-1}$ (Fig. 8c and d) showed no significant change in the integrated area of the curve under bending, indicating the excellent flexibility of the device. The electrochemical performance of the two supercapacitors with different bending times was also characterized. As shown in Fig. $8 \mathrm{~g}$, $\mathrm{h}$ and $\mathrm{i}$, both the $\mathrm{CPC}_{10}$ and $\mathrm{CPR}_{10}$ electrodes still have good flexibilities in bent states and have the capacitance retention of $97.44 \%$ and $93.47 \%$ after 100 bending times, respectively. Even after 200 bending times, the capacitance retention still have $76.58 \%$ and $75.94 \%$, respectively. The stress-strain data also showed that the tensile strengths of $\mathrm{CPC}_{10}$ and $\mathrm{CPR}_{10}$ electrodes were 2.83 and $3.19 \mathrm{MPa}$, respectively, which were shown in Fig. S10b. $\uparrow$ The above results showed that both electrodes had good flexibility properties.

\section{Conclusions}

In summary, we propose a simple LbL assembly of PANi/ CMWCNT and PANi/RGO composites on CNF aerogels with a fibrillar porous network structure via drip and vacuum filtration, in order to obtain nanocomposite electrodes. The nanoactive materials deposited on the nanofibril scaffolds showed uniformly distributed multilayer nanoarchitectures, especially in the case of the $\mathrm{CPC}_{n}$ aerogels. The CNF aerogels with a highly porous and accessible nanofibrillar network not only provide a large surface area for the nano-active materials without agglomeration, but also allow for efficient diffusion and permeation of the electrolyte ions. This unique structure imparts $\mathrm{CPC}_{10}$ and $\mathrm{CPR}_{10}$ with high gravimetric specific capacities of 965.80 and $780.64 \mathrm{~F} \mathrm{~g}^{-1}$, respectively, during threeelectrode testing. In addition, high areal specific capacitances of 1.59 and $1.46 \mathrm{~F} \mathrm{~cm}^{-2}$ and good energy densities of 147.23 and $112.32 \mathrm{~mW} \mathrm{~h} \mathrm{~cm}^{-2}$, respectively, are observed during twoelectrode testing. The electrodes show excellent rate capability as well as good durability and flexibility without obvious curve abnormity at different bending angles. We believe that this LbL assembly method using an aerogel is a simple and effective means of creating nanostructured electrodes for green and flexible energy storage devices.

\section{Conflicts of interest}

There are no conflicts to declare.

\section{Acknowledgements}

This work was supported by the Special Fund for Forest Scientific Research in the Public Welfare (No. 201504603) and the Fundamental Research Funds of CAF (No. CAFYBB2017ZX003).

\section{References}

1 J. He, N. Wang, Z. Cui, H. Du, L. Fu, C. Huang, Z. Yang, X. Shen, Y. Yi and Z. Tu, Nat. Commun., 2017, 8, 1172.

2 X. W. Wang, H. P. Guo, J. Liang, J. F. Zhang, B. Zhang, J. Z. Wang, W. B. Luo, H. K. Liu and S. X. Dou, Adv. Funct. Mater., 2018, 28, 1801016.

3 A. Choudhury, J.-H. Kim, S. Sinha Mahapatra, K.-S. Yang and D.-J. Yang, ACS Sustainable Chem. Eng., 2017, 5, 2109-2118.

4 D. Zhao, C. Chen, Q. Zhang, W. Chen, S. Liu, Q. Wang, Y. Liu, J. Li and H. Yu, Adv. Energy Mater., 2017, 7, 1700739.

5 S. Kanaparthi and S. Badhulika, Sens. Actuators, B, 2017, 242, 857-864.

6 L. Yu, L. Hu, B. Anasori, Y.-T. Liu, Q. Zhu, P. Zhang, Y. Gogotsi and B. Xu, ACS Energy Lett., 2018, 3, 1597-1603.

7 J. Zhu, S. Tang, J. Wu, X. Shi, B. Zhu and X. Meng, Adv. Energy Mater., 2017, 7, 1601234. 
8 A. Ramadoss, K.-Y. Yoon, M.-J. Kwak, S.-I. Kim, S.-T. Ryu and J.-H. Jang, J. Power Sources, 2017, 337, 159-165.

9 T. Qin, S. Peng, J. Hao, Y. Wen, Z. Wang, X. Wang, D. He, J. Zhang, J. Hou and G. Cao, Adv. Energy Mater., 2017, 7, 1700409.

10 Y. Ko, M. Kwon, W. K. Bae, B. Lee, S. W. Lee and J. Cho, Nat. Commun., 2017, 8, 536.

11 G. Tang, L. Cao, P. Xiao, Y. Zhang and H. Liu, J. Power Sources, 2017, 355, 1-7.

12 X. Zhang, J. Wang, J. Liu, J. Wu, H. Chen and H. Bi, Carbon, 2017, 115, 134-146.

13 Y. Shi, L. Peng, Y. Ding, Y. Zhao and G. Yu, Chem. Soc. Rev., 2015, 44, 6684-6696.

14 D. P. Dubal, O. Ayyad, V. Ruiz and P. Gomez-Romero, Chem. Soc. Rev., 2015, 44, 1777-1790.

15 M. F. Mousavi, M. Hashemi, M. S. Rahmanifar and A. Noori, Electrochim. Acta, 2017, 228, 290-298.

16 C. B. Bucur, M. Jones, M. Kopylov, J. Spear and J. Muldoon, Energy Environ. Sci., 2017, 10, 905-911.

17 M. Jana, S. Saha, P. Samanta, N. C. Murmu, N. H. Kim, T. Kuila and J. H. Lee, J. Power Sources, 2017, 340, 380-392.

18 W. A. Marmisollé and O. Azzaroni, Nanoscale, 2016, 8, 98909918.

19 F.-X. Xiao, M. Pagliaro, Y.-J. Xu and B. Liu, Chem. Soc. Rev., 2016, 45, 3088-3121.

20 S. R. Kwon, M. B. Elinski, J. D. Batteas and J. L. Lutkenhaus, ACS Appl. Mater. Interfaces, 2017, 9, 17125-17135.

21 Z. Zhou, W. Panatdasirisuk, T. S. Mathis, B. Anasori, C. Lu, X. Zhang, Z. Liao, Y. Gogotsi and S. Yang, Nanoscale, 2018, 10, 6005-6013.

22 G. Nyström, A. Marais, E. Karabulut, L. Wågberg, Y. Cui and M. M. Hamedi, Nat. Commun., 2015, 6, 7259.

23 S. Lyu, Y. Chen, S. Han, L. Guo, Z. Chen, Y. Lu, Y. Chen, N. Yang and S. Wang, RSC Adv., 2018, 8, 13191-13199.

24 N. Lavoine and L. Bergström, J. Mater. Chem. A, 2017, 5, 16105-16117.

25 K. J. De France, T. Hoare and E. D. Cranston, Chem. Mater., 2017, 29, 4609-4631.
26 W. Chen, H. Yu, S.-Y. Lee, T. Wei, J. Li and Z. Fan, Chem. Soc. Rev., 2018, 47, 2837-2872.

27 F. Jiang, T. Li, Y. Li, Y. Zhang, A. Gong, J. Dai, E. Hitz, W. Luo and L. Hu, Adv. Mater., 2018, 30, 1703453.

28 T. Saito and A. Isogai, Biomacromolecules, 2004, 5, 19831989.

29 Y. Shao, M. F. El-Kady, C. W. Lin, G. Zhu, K. L. Marsh, J. Y. Hwang, Q. Zhang, Y. Li, H. Wang and R. B. Kaner, Adv. Mater., 2016, 28, 6719-6726.

30 F. Jiang and Y.-L. Hsieh, ACS Appl. Mater. Interfaces, 2014, 6, 20075-20084.

31 Y. Li, Z. Y. Fu and B. L. Su, Adv. Funct. Mater., 2012, 22, 46344667.

32 J.-W. Jeon, S. R. Kwon and J. L. Lutkenhaus, J. Mater. Chem. $A, 2015,3,3757-3767$.

33 M. N. Hyder, S. W. Lee, F. Ç. Cebeci, D. J. Schmidt, Y. ShaoHorn and P. T. Hammond, ACS Nano, 2011, 5, 8552-8561.

34 L. Zhang, D. Huang, N. Hu, C. Yang, M. Li, H. Wei, Z. Yang, Y. Su and Y. Zhang, J. Power Sources, 2017, 342, 1-8.

35 S. Y. Kim, J. Hong, R. Kavian, S. W. Lee, M. N. Hyder, Y. ShaoHorn and P. T. Hammond, Energy Environ. Sci., 2013, 6, 888897.

36 L. Shao, J.-W. Jeon and J. L. Lutkenhaus, J. Mater. Chem. A, 2013, 1, 7648-7656.

37 T. Lee, T. Yun, B. Park, B. Sharma, H.-K. Song and B.-S. Kim, J. Mater. Chem., 2012, 22, 21092-21099.

38 A. K. Sarker and J.-D. Hong, Langmuir, 2012, 28, 1263712646.

39 J. Luo, Q. Ma, H. Gu, Y. Zheng and X. Liu, Electrochim. Acta, 2015, 173, 184-192.

40 X. Yang, K. Shi, I. Zhitomirsky and E. D. Cranston, Adv. Mater., 2015, 27, 6104-6109.

41 X. Wang, K. Gao, Z. Shao, X. Peng, X. Wu and F. Wang, J. Power Sources, 2014, 249, 148-155.

42 S. Zeng, H. Chen, F. Cai, Y. Kang, M. Chen and Q. Li, J. Mater. Chem. A, 2015, 3, 23864-23870.

43 Q. Zhou, Y. Li, L. Huang, C. Li and G. Shi, J. Mater. Chem. A, 2014, 2, 17489-17494. 